\title{
BMJ Open Quality and safety in the transitional care of the elderly (phase 2): the study protocol of a quasi-experimental intervention study for a cross-level educational programme
}

\author{
Marianne Storm, ${ }^{1}$ Oliver Groene,${ }^{2}$ Ingelin Testad, ${ }^{1,3}$ Dagrunn N Dyrstad, ${ }^{1,4}$ \\ Randi N Heskestad, ${ }^{1}$ Karina Aase ${ }^{1,3}$
}

To cite: Storm M, Groene 0, Testad I, et al. Quality and safety in the transitional care of the elderly (phase 2): the study protocol of a quasiexperimental intervention study for a cross-level educational programme. BMJ Open 2014;4:e005962. doi:10.1136/bmjopen-2014005962

- Prepublication history for this paper is available online. To view these files please visit the journal online (http://dx.doi.org/10.1136/ bmjopen-2014-005962)

Received 23 June 2014 Accepted 4 July 2014

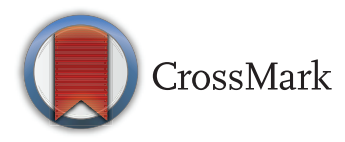

For numbered affiliations see end of article.

Correspondence to Dr Marianne Storm, Department of Health Studies, University of Stavanger, Stavanger 4036, Norway;

marianne.storm@uis.no

\section{ABSTRACT}

Introduction: Transitional care and patient handover are important areas to ensure quality and safety in elderly healthcare services. Previous studies showed that healthcare professionals have little knowledge of the setting they are transferring patients to and a limited understanding of roles and functions; these constitute barriers to effective communication and shared care responsibilities across levels of care. Aim: The main objective is to implement a cross-level education-based intervention programme with healthcare professionals aimed at (1) increasing professionals' awareness and competencies about quality and safety in the transitional care of the elderly; (2) creating a discussion platform for knowledge exchange and learning across levels and units of care and (3) improving patient safety culture, in particular, in transitional care.

Methods and analysis: A quasi-experimental control group study design with an intervention group and a control group; this includes a pretest, post-test and 1year follow-up test assessment of patient safety culture. Qualitative data will be collected during the intervention programme and between the measurements. The study design will be beneficial for addressing the effects of the cross-level educational intervention programme on reports of patient safety culture and for addressing the feasibility of the intervention measures.

Ethics and dissemination: The study has been approved by the Regional Committees for Medical and Health Research Ethics in Norway, Ref. No. 2011/1978. The study is based on informed written consent; informants can withdraw from the study at any point in time. The results will be disseminated at research conferences, in peer review journals and through public presentations outside the scientific community.

\section{INTRODUCTION}

Transitional care and patient handover are important areas addressed by the WHO to

\section{Strengths and limitations of this study}

- The study creates a cross-level educational programme for healthcare professionals to add to the knowledge of influential components on quality and safety in transitional care of the elderly.

- A unique feature of the study is that the effects of the cross-level educational intervention will be assessed on reports of patient safety culture in hospital and nursing home wards. Feasibility of the intervention measures in promoting learning and knowledge exchange across levels and units of care will be assessed through the use of qualitative data.

- Study challenges relate to barriers to interprofessional collaboration across levels of care, leadership support, turnover of healthcare professionals, organisational restructuring and engaging healthcare professionals to report on the repeated measures of patient safety culture.

ensure quality and safety in healthcare services. ${ }^{1}$ Coleman and Boult ${ }^{2}$ defined transitional care as a set of actions designed to ensure the coordination and continuity of healthcare, as patients transfer between different locations (eg, from a hospital to a nursing home for the elderly) or between different levels of care within the same location. Patient handover is a key element in transitional care and includes the handover of patient information, communication between involved healthcare personnel and the transfer of care responsibility. ${ }^{3}$ Jeffcott et $a t^{4}$ consider the transfer of (1) information, (2) professional responsibility and/or accountability between individuals and teams and (3) the context of teams and their work environment as vital in clinical handovers. 
A particularly vulnerable patient group in transitional care are elderly persons aged $>75$ years with complex health conditions. ${ }^{5}{ }^{6}$ These patients often receive healthcare services from numerous service providers in different healthcare settings. Consequently, they are at risk of repeated hospitalisations and adverse events (eg, medication errors, delays in treatment). ${ }^{3} 57$

Professional cultures in hospitals and community health services can include healthcare professionals who have little knowledge of the setting they are transferring their patients to. A limited understanding of healthcare professional's roles and functions constitutes a barrier to effective communication and the sharing of care responsibilities across levels of care ${ }^{7-10}$ Many professionals lack attention, time and resources in both the hospital and community settings. This can lead to ineffective transitional care processes. ${ }^{811}$

The literature reveals a variety of targeted interventions, often used in combination, to improve the quality and safety in transitional care of the elderly. These interventions include a key coordinator for discharge, a systematic discharge planning, standardised discharge summaries, including medication reports, the education of patients and families, pharmacy interventions/reconciliations and curriculum interventions. ${ }^{12}{ }^{13}$ Despite promising efforts, there are concerns that these targeted interventions will not be sufficient enough to address the complexity and diversity of the transitional care of the elderly who are aged $>75$ with complex health conditions. A lack of awareness of the challenges of transitional care among healthcare professionals and not viewing transitional care as a core area of competence in caring for the elderly are important concerns. ${ }^{6}$

A systematic review of educational interventions aimed at healthcare professionals to improve handover by Gordon and Finley $^{14}$ reported a general paucity in research within the area. They identified nine studies reporting improved attitudes or knowledge and skills and one study demonstrating the transfer of handover skills to the work place. However, none of the studies reported that handover education could improve patient outcomes. The authors emphasised a need to identify the core components in transitional care education when aiming to improve handover in healthcare. The European HANDOVER Project suggests both education and pedagogical tools aimed at healthcare professionals to improve patient handover. ${ }^{11} 15$

Training or educational interventions with healthcare personnel can be conducted as formal instructor led planned training, workplace learning interventions guided by explicit and measurable goals and as interventions aimed at redesigning clinical microsystems. ${ }^{11}$ Curricula interventions (eg, teaching transitional care practices) have been rated as useful for increasing knowledge about adverse events in transitional care, especially for competence in discharging chronically ill patients in a safer manner and for educating patients on discharge medications. ${ }^{12}$
Job rotation and discussion platforms are suggested as useful ways of developing a mutual understanding of professionals' role, tasks and responsibilities among healthcare staff across care levels. ${ }^{16}$ Laugaland et al ${ }^{12}$ argued for involving multiple professional groups when aiming to improve transitional care, as different groups have complementary perspectives necessary for optimal patient care. Teaching methods in educational interventions can include exercises based on simulation scenarios and role-play, group discussions and lectures focusing on adverse events and patient safety. ${ }^{14} 17$

The observational data collected in phase 1 of the 'Quality and safety in transitional care of the elderly' project suggests the importance of addressing multiple, interrelated factors. ${ }^{6}{ }^{18}$ Such factors are healthcare professionals' competencies about transitional care, the transfer of information and communication among professional groups, the organisation of work tasks and resources, the healthcare needs and co-morbidities of the elderly patient and the perspectives and role of the patient and their next of kin in transitional care. ${ }^{6}$ Covering some or all of these factors in an educational intervention programme could increase awareness and influence healthcare professionals' handover knowledge and skills across levels and units of care, subsequently contributing to organisational cultures improving on quality and safety in transitional care of the elderly.

The study protocol constitutes phase 2 of the 'Quality and safety in transitional care of the elderly' project. ${ }^{18}$ The objective of this quasi-experimental intervention study is to conduct a cross-level educational intervention programme with healthcare professionals in primary and secondary healthcare services aimed at (1) increasing professionals' awareness and competencies about quality and safety in the transitional care of the elderly; (2) creating a discussion platform for knowledge exchange and learning across levels and units of care and (3) improving patient safety culture, in particular in transitional care.

The following research questions will be addressed:

1. How can an educational intervention programme improve healthcare professionals' awareness and competencies about quality and safety in transitional care?

2. How can a discussion platform serve as a feasible arena for knowledge exchange and learning among professionals across levels and units of care?

3. What is the impact of an educational intervention programme on healthcare professionals' reports on safety culture?

\section{METHODS}

\section{Design and selection}

A quasi-experimental control group study design with an intervention group and control group receiving a pretest, post-test and 1-year follow-up measure will be applied. The study will be conducted in the period 
autumn 2013 to spring 2015, in one geographical area, in one Norwegian Regional Health Authority. The study will be carried out at the ward level. The study population will be healthcare professionals working in specialist healthcare services (different wards in one city-based university hospital) and healthcare professionals working in nursing homes in one municipality. The hospital wards selected for intervention and control groups will be from two sections (internal medicine and emergency) within the same hospital, while nursing home wards will be selected from three different nursing homes.

Healthcare professionals in the intervention group will be from two wards at the city-based university hospital: the internal medicine ward for pulmonary diseases and one emergency ward, and from two nursing home wards (an intermediate care ward/short-time ward) in two nursing homes in the municipality.

A control group will include healthcare professionals working in three hospital wards (a renal disease internal medicine ward, an infection medicine internal medicine ward and the observational unit of an emergency ward) and three short-time wards in one nursing home that is not taking part in the intervention programme.

The hospital and nursing home wards will be selected based on their similarities with regard to the number of employees, the number of patient beds and their frequent involvement in, and organisation of, work tasks for the transitional care of the elderly. The study sites and wards are presented in figure 1 .

A formal request will be made to the leaders at the hospital wards and nursing homes, with information about participation in the study. This will be followed by short meetings between the leaders and the research team to elaborate on the pretest and post-test measures, the intervention programme and the requirements for participation. Emphasis will be placed on ensuring leader support and willingness from the staff to participate in the study. If the hospital and nursing home wards agree to participate in the cross-level educational intervention programme, an official introduction of the intervention will be given by the research team during staff meetings. Hospital and nursing home control wards will be recruited in a similar manner to the intervention wards, but there will be no introduction of the intervention.

We aim to include all members of the healthcare staff (eg, nurses, nursing assistants, physicians, physiotherapists, ward leaders) in the intervention wards to participate in the cross-level educational intervention programme. Participants from the hospital and nursing home control wards receiving only the pretest and post-test measures will be nurses, physicians, nursing assistants, physiotherapists and ward leaders. The main inclusion criterion for professionals to take part in the measurements and intervention will be that they are employed for at least a half-time position, if not for a full time position. People who work less than half-time will not be included.

In this study, blinding of the study participants or those administering the intervention or assessing the outcomes will not be possible.

\section{Cross-level educational intervention}

A cross-level educational intervention, called the 'Meeting Point', consists of an educational part and a discussion platform for healthcare professionals from different professions (eg, nurses, doctors, physiotherapists), wards and levels of care (eg, hospital and municipality). The 'Meeting Point' will be conducted three times, as half-day seminars, over a 5-month period with professionals from hospital and nursing home wards. The intervention will be delivered at a centre for simulation and training used by healthcare professionals, and will be conducted during weekday work hours. Each seminar will address three thematic perspectives on quality and safety in transitional care: (1) risk factors, (2) patient perspectives and (3) system perspectives. Every seminar will be organised around four pillars: an introduction, a teaching session, a group work activity and a plenary discussion. Seminars will be facilitated by the members of the research team. Each seminar will be run three times to accommodate participation from staff in all the wards and to have a group of 30-40 participants at each 'Meeting Point' seminar.
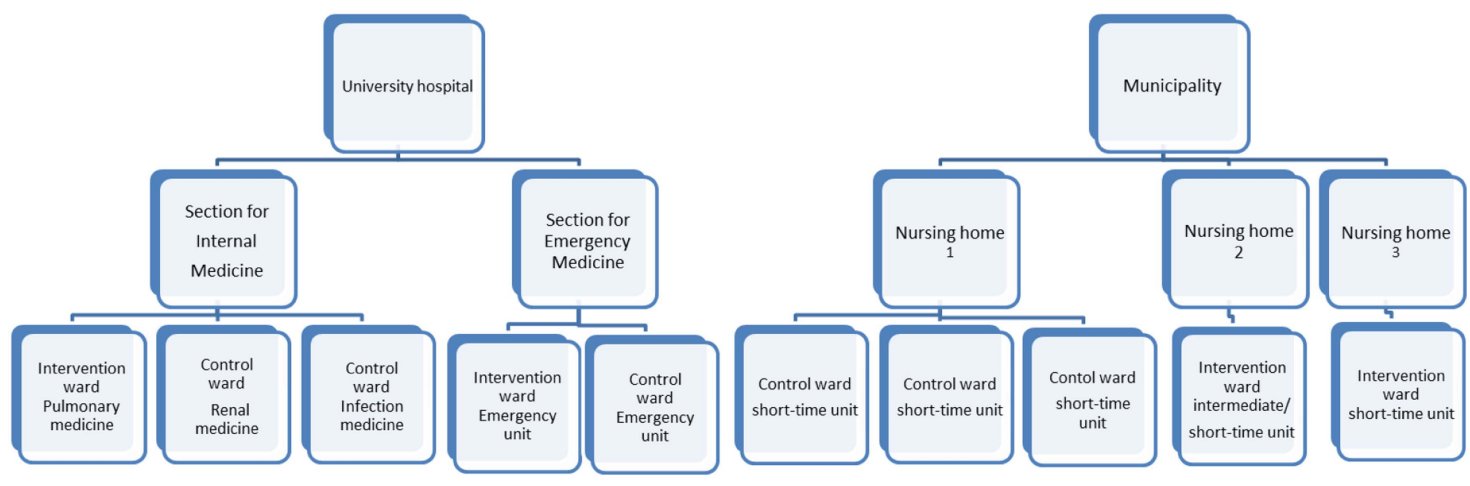

Figure 1 Study sites and wards. 
Each seminar will start with one or several of the members of the research team welcoming the participants, introducing the current thematic area and the seminar objectives. At the first seminar, there will be a short presentation about phase 1 of the 'Quality and safety in transitional care of the elderly' project. ${ }^{6}{ }^{18}$ At the second and third seminars, participant evaluations and identified measures from the previous seminar will be presented in order to maintain focus and to track recent activities at the 'Meeting Point' and in the wards.

To increase competencies and the awareness of quality and safety in the transitional care of the elderly, the seminar will begin with a $1 \mathrm{~h}$ teaching session held by one or several of the members of the research team. The session will provide an overview of the current thematic area and introduce specific and evidence-based tools to support and improve quality and safety in transitional care. Group activity and discussions will be used to stimulate cross-unit dialogues and collaboration between the participants related to improving quality and safety in transitional care. The groups will be mixed across professional groups and care levels and will vary in size from five to eight members. Each group will be facilitated by a member of the research team. The group work activity will last for approximately $1 \mathrm{~h}$.

To focus the participants' attention on each of the three thematic areas (risk factors, patient perspectives and system perspectives), we will use scenarios and exercises for the discussion and group work activity. Two scenarios will be developed by the research team. The scenarios will be based on observational data collected in phase 1 of the 'Quality and safety in transitional care of the elderly' project. ${ }^{6} 18$

The first scenario will be a text-based patient-case, illustrating risks associated with transitional care. The second scenario will be a film illustrating the patient perspective in the admission and discharge process of elderly patients. A third scenario will be a film made by the regional health authority illustrating systems for coordination in transitional care. All three scenarios will be followed up by asking the group participants two to four questions to be approached individually and as a group. The scenarios will be used to stimulate individual reflection on current transitional care practices and to engage the participants in group discussions about current practices, existing challenges and identification of improvement measures. A stepwise approach will be used for the identification of measures to improve transitional care at the ward level, in the hospital and nursing homes. Each group participant will individually suggest measures and present these measures to the group members for discussion. The group will agree on three key measures within each of the three thematic areas (risk, patient, system). Each group will then present their measures, as part of the plenary sessions, for discussions and agreements for further action in the hospital and nursing home wards (table 1).
Contextual issues in Norwegian healthcare

In 2012, the Coordination Reform was implemented in Norway to improve transitional care. ${ }^{19}$ Primary issues in the reform process include improving coordination of healthcare services and ensuring that patients experience continuity of care and high-quality services. The Coordination Reform introduces a binding system of agreements for the organisation of hospital admission and discharge processes, as well as the handover of information and cooperation between hospitals and municipal healthcare services.

The Norwegian Ministry of Health and Care Services launched a patient safety campaign, 'In Safe Hands', during the period $2011-2013 .{ }^{20}$ In 2014 , the campaign was continued as a 5-year programme aiming to reduce patient harm in primary and specialist healthcare services. A focus in the campaign is on measuring patient safety culture among professionals in hospitals using a Norwegian version of the Safety Attitudes Questionnaire. ${ }^{21} 22$

Interprofessional collaboration and teamwork within and across clinical settings are considered an essential feature of high-quality healthcare. ${ }^{23}{ }^{24} \mathrm{Clark}^{23}$ suggests relatively equal status of all the healthcare professions in Norway, as this is considered important for stimulating mutual professional respect and inter-professional collaborations. Traditional hierarchical lines of responsibilities and communication between the healthcare professions have been reported within the hospital setting in Norway, where physicians have an autonomous and independent role with weaker interpersonal ties with other hospital professionals. ${ }^{25}$

\section{Data collection and measurements \\ Quantitative data}

A questionnaire will be administered to the healthcare professionals before the intervention programme (t1), at the end of the intervention period (to assess shortterm effects) (t2), and 12 months after the intervention (to assess long-term effects) (t3). The questionnaire will be administered to the study participants at work with the opportunity to complete the questionnaire during, or after, work hours.

Safety culture is considered an important foundation for improving patient safety and quality of care. ${ }^{26}$ Patient safety culture relates to healthcare personnel's attitudes, values, norms and behaviours within a healthcare organisation. $^{27} 28$ The questionnaire administered to hospital healthcare professionals will contain the Hospital Survey on Patient Safety Culture (HSOPSC), ${ }^{29}$ which has proven to be a valid measurement scale for Norwegian specialist healthcare services. ${ }^{30}$ The Patient Safety Culture measurement scale is adapted to staff in nursing homes and is referred to as the 'Nursing Home Survey on Patient Safety Culture' (NHSPSC). ${ }^{31}$ The NHSPSC measure has recently been translated into Norwegian, in accordance with a standardised seven-step process recommended by the Agency for Healthcare Research and Quality. ${ }^{31}$ These measurement scales will enable the 
Table 1 Key element in the cross-level educational intervention programme 'Meeting Point'

\begin{tabular}{|c|c|c|c|}
\hline Elements & $\begin{array}{l}\text { Approximate } \\
\text { time (min) }\end{array}$ & Contents & Purpose \\
\hline $\begin{array}{l}\text { Introduction by a member of } \\
\text { the research team }\end{array}$ & $15 \min$ & $\begin{array}{l}\text { Seminar 1: Project presentation } \\
\text { 'Quality and safety in transitional } \\
\text { care of the elderly' } \\
\text { Seminars } 2 \text { and } 3 \text { : Welcome and } \\
\text { summary of previous seminar, } \\
\text { participant evaluations and } \\
\text { identified measures }\end{array}$ & $\begin{array}{l}\text { Introduce the participants to the } \\
\text { research project, its main purpose } \\
\text { and current status } \\
\text { Keep focus during the intervention } \\
\text { and track recent activities at the } \\
\text { 'Meeting Point and in the wards }\end{array}$ \\
\hline $\begin{array}{l}\text { Teaching sessions held by } \\
\text { one or several of the } \\
\text { research team members }\end{array}$ & $45 \mathrm{~min}$ & $\begin{array}{l}\text { Three thematic areas: } \\
\text { Risk factors } \\
\text { Patient perspectives } \\
\text { System perspectives }\end{array}$ & $\begin{array}{l}\text { Increase awareness and } \\
\text { competencies of quality and safety in } \\
\text { transitional care of the elderly } \\
\text { Introduce evidence and tools to } \\
\text { improve quality in transitional care }\end{array}$ \\
\hline $\begin{array}{l}\text { Scenarios developed by the } \\
\text { research team and the } \\
\text { regional health authority }\end{array}$ & $15 \mathrm{~min}$ & $\begin{array}{l}\text { Text-based patient case of risks } \\
\text { factors } \\
\text { Film illustrating the patient } \\
\text { perspective } \\
\text { Film illustrating the system } \\
\text { perspective }\end{array}$ & $\begin{array}{l}\text { Focus attention to the three thematic } \\
\text { areas to stimulate individual reflection } \\
\text { and group activity }\end{array}$ \\
\hline $\begin{array}{l}\text { Group activity in mixed } \\
\text { groups across professions, } \\
\text { wards, and care levels }\end{array}$ & $1 \mathrm{~h}$ & $\begin{array}{l}\text { Focus on } 2-3 \text { questions developed } \\
\text { by the research theme in relation to } \\
\text { the scenarios. } \\
\text { Identify measures to improve } \\
\text { transitional care at the ward level }\end{array}$ & $\begin{array}{l}\text { To stimulate cross-unit, cross-level } \\
\text { and inter-professional learning and } \\
\text { knowledge exchange between the } \\
\text { participants }\end{array}$ \\
\hline $\begin{array}{l}\text { Plenary discussion led by } \\
\text { members of the research } \\
\text { team }\end{array}$ & $45 \mathrm{~min}$ & $\begin{array}{l}\text { Group presentations of } \\
\text { improvement measures identified } \\
\text { and agreed upon }\end{array}$ & $\begin{array}{l}\text { Discussion and agreement of } \\
\text { measures for implementation at the } \\
\text { wards }\end{array}$ \\
\hline $\begin{array}{l}\text { Follow-up meeting with } \\
\text { healthcare professionals at } \\
\text { the nursing home and } \\
\text { hospital wards }\end{array}$ & $1 \mathrm{~h}$ & $\begin{array}{l}\text { Group interview with } 4-5 \text { key } \\
\text { questions to assess if and how } \\
\text { improvement measures have been } \\
\text { implemented at the wards }\end{array}$ & $\begin{array}{l}\text { Identification of drivers and barriers to } \\
\text { implementation of measures to } \\
\text { improve quality in transitional care }\end{array}$ \\
\hline
\end{tabular}

assessment of improvements in safety culture following participation in cross-level intervention.

The HSOPSC contains 44 items and covers the following dimensions measuring the safety climate at the unit/ ward level: communication openness; feedback and communication about errors; organisational learningcontinuous improvement; supervisor/management expectations and actions promoting safety; non-punitive responses to errors; staffing; teamwork within units and the three dimensions at the hospital level. These three dimensions include handoffs and transitions, management support for patient safety and teamwork across units. The scale includes outcome measures: (1) overall perception of patient safety and frequency of events reported and (2) two single-item scales: patient safety grading and the number of reported events over the last 12 months. $^{29}$

The NHSPSC was modelled after the HSOPSC after an extensive review of the nursing home safety literature and discussions with researchers and nursing home administrators. $^{32}$ There are some minor changes in items and domain wording between the hospital and nursing home versions (eg, the term resident is used in the nursing home version to replace 'patient' used in the HSOPSC). ${ }^{32}$ The measure includes 44 items and the following corresponding domains of the HSOPSC: teamwork; supervisor/manager expectations and actions promoting resident safety; management support for resident safety; organisational learning; overall perception of resident safety; feedback and communication about incidents; communication openness; staffing; handoffs; non-punitive responses to mistakes; compliance with procedures; and training and skills. In addition, the scale includes outcome measures related to respondents' perceptions of (1) whether they would tell a friend this is a safe nursing home for their family and (2) an overall rating of resident safety.

\section{Qualitative data}

It is argued that patient safety strategies and improvement initiatives would benefit from evaluations using both quantitative and qualitative methodologies, as qualitative data can provide valuable information in the contextual setting. ${ }^{28}$ As an integrated part of the 'Meeting Point', qualitative data will be collected in terms of written feedback from participants on the key components of the cross-level educational intervention (teaching sessions, group work activities and plenary 
sessions), minutes from the plenary sessions, log reports from group work facilitators, and study participants' written notes from the group-work activities. Observations of the 'Meeting Point' seminars will be performed with a specific focus on learning and knowledge exchange between participants and across levels of care (hospital and nursing homes).

In order to follow -up on the implementation of improvement measures in the intervention wards, we will perform one or two meetings with ward leaders and other relevant personnel following the 'Meeting Point' seminars and after the second measurement (t2). To obtain an overview of the quality and safety activities in the comparison group, conversations with ward leaders and/or key stakeholders at the control wards following the second measurement will be conducted (t2).

\section{Data analysis and statistical power}

\section{Outcome data}

The primary outcome measures in this study are reports on the patient safety culture dimensions measuring the safety climate at the unit/ward level. We will use qualitative data to assess the feasibility of the intervention measures in increasing participants' awareness and competencies about quality in transitional care, and also for assessing experiences from participating in the intervention.

\section{Analysis of qualitative data}

The qualitative data material will be used to evaluate how the cross-level educational intervention programme contributed to healthcare professionals' awareness and competencies about quality and safety in transitional care. The data will also be used to assess the feasibility of creating a discussion platform for healthcare professionals by promoting learning and knowledge exchange across levels (hospital, nursing homes) and units of care.

The theoretical framework for understanding knowledge creation and interorganisational knowledge transfer will be based on Nonaka and Takeuchi ${ }^{33}$ and Easterby-Smith $e t a l^{44}$ and will be used in the analysis of the observational data. Data will be coded according to the dimensional types of knowledge creation (socialisation, combination, externalisation and internalisation), interorganisational dynamics (social ties, confidence, power and structures) and characteristics of the actors (absorptive capacity, motivation and transferability).

\section{Analysis of quantitative data}

To measure the effects of the intervention on the reports of patient safety culture and detect differences between the intervention and control group, sample size estimates will be conducted. The calculations use the HSOPSC. ${ }^{29}$ To estimate the sample size, we will use the results from a Norwegian study conducted by Olsen and Aase. ${ }^{30}$ The study includes participants employed at the same university hospital, as included in this study.
We hypothesise that the intervention groups' reporting of patient safety culture will improve by $10 \%$ following participation in the intervention. The required sample size for the two-sample t test comparisons of the means (with a power of $80 \%$ ) is estimated to be 75 people for the intervention group and 150 people for the control group. Thus, a total sample size of 225 people will need to be recruited.

The statistical software package, SPSS V.21, will be used for the statistical data analysis. Descriptive analysis will be performed to illustrate the distribution of variables in the intervention and the control group. To reveal the potential differences between the healthcare professionals in the intervention group and the control group, $\chi^{2}$ statistics will be conducted and will focus on the following variables: professional background, years of employment at hospital/nursing home, work hours per week, patient contact and years of professional experience. The computation of the mean scores for each of the dimensions in the patient safety culture measure and tests of reliability will be performed to assess the internal consistency of the subscales.

The multiple regression analysis will be a hierarchical mixed linear model with each of the patient safety culture dimensions as dependent variables to calculate the effects of the intervention (the independent variable). ${ }^{27}$ We will separately test the effect of time, the effect of intervention and the effect of time interacting with intervention by using data from the first (T1), second (T2) and third measurements (T3) of the intervention and the control groups.

Non-responders can be a problem when conducting studies with repeated measurements. The mixed linear model is beneficial in this way, as it includes participants responding only to one or two of the measurements. ${ }^{27} 35$ We will also perform an analysis to assess possible significant differences between responders and nonresponders. Variables under consideration include professional background, work hours per week, direct patient contact and years of employment at the hos$\mathrm{pital} /$ nursing home.

\section{Ethics and dissemination}

The study is based on informed written consent. As such, participation is voluntary and informants can withdraw from the study at any point in time. The privacy of the participants responding to the questionnaires will be protected. All survey data collected will be kept separate from the respondents' names, for anonymity purposes. Qualitative and quantitative data related to the study will be stored on a protected server and can only be accessed by selected members of the research team.

Study results are to be disseminated at several congresses and research conferences, as well as in peerreviewed journals. In addition, study results will be presented to stakeholders outside the academic community. 


\section{DISCUSSION}

The literature has revealed that interventions to improve quality and safety in healthcare are divided into different categories. There are targeted service interventions, conducted near patients, to improve clinical processes (eg, a guideline for the administration of a therapeutic intervention). There are also generic service interventions performed far away from the patients (eg, a training programme for healthcare professionals to improve patient safety culture). ${ }^{36}$

Generic interventions are complex and can have diffuse effects, as they can impact various clinical processes and outcomes in a hospital (eg, adverse events, patient satisfaction and mortality). ${ }^{36} 37$ Measuring the effectiveness of a generic intervention (eg, an educational programme for healthcare professionals) can require extensive resources and a large sample size, in particular, for being able to measure the effects at the patient level. Lilford et $a l^{36}$ argued for using outcome measures in which a number of processes can converge. Consequently, we study the effect of a cross-level educational intervention on professionals' reports of patient safety culture. The hospital and nursing home safety culture measure covers multiple and relevant aspects of quality and safety in healthcare and in transitional care. The scale has been reported to be sensitive to measure change over time, both at the ward and hospital/ nursing home level. ${ }^{27} 30$

Reported barriers to interprofessional collaboration across levels of care are found to be related to structural issues (eg, sufficient time, resources and structural support), role issues (eg, overlap of domains for involved professionals) and professionals lacking adequate teamwork skills. ${ }^{23}$ We will establish a discussion platform for cross-level learning and knowledge exchange to stimulate a common understanding of the roles and functions of healthcare professionals in the transitional care of the elderly. This can promote an organisational culture where professionals take responsibility for quality and safety in transitional care. During the 'Meeting Point', we will observe cross-level and interprofessional interactions, dialogues and knowledge exchanges, as part of the group work activity and the social setting.

Some issues related to sample size need to be addressed when conducting repeated measurements. We have conducted power analyses to ensure a proper sample size to estimate a significant improvement in reports of patient safety culture. Repeated measurements increase the likelihood for non-responses at one or several of the measurements. This might be a particular issue in the control group, which will not be taking part in the intervention activities. All study participants will receive a questionnaire at work with the opportunity to complete the questionnaire during, or after, work hours. As such, a statistical analysis employing a multiple linear modelling procedure is considered beneficial. $^{35}$
The hospital intervention and control groups in this study will be recruited within the same hospital organisation, while nursing home wards will be recruited from three nursing homes in the same municipality. We will include and compare hospital wards that are similar with respect to size, number of beds and number of staff. The organisation of the work tasks and routines for transitional care is similar across the hospital wards, due to statutory and formalised agreements between the hospital and the belonging municipality. ${ }^{38} 39$ These are important issues to assess when measuring the effect of the intervention on reports of patient safety culture.

There is a risk of 'contamination' or 'diffusion of treatment' when intervention and control group participants are recruited from the same organisation, as they can communicate about the intervention. Individuals can be interested in taking part in what they perceive to be a 'desirable' intervention. ${ }^{40}$ We believe that a particular challenge within hospital organisations is the lack of communication and teamwork across wards. The HSOPC dimension, 'teamwork across units', received some of the lowest average scores in two Norwegian studies. ${ }^{27} 30$ Therefore, we believe that the risk of healthcare professionals communicating about the intervention across the hospital wards is relatively small. In addition, the intervention programme will not be introduced or communicated to the control group participants. To avoid the intervention becoming associated with specific benefits, it will be conducted during weekday work hours.

There are barriers to organisational change in complex healthcare institutions, in particular, in hospitals with a multifaceted and high number of staff. This might affect the commitment to continue to work to improve quality and safety in transitional care. Factors that may hamper the implementation of quality improvement measures include lack of leadership follow-up, the turnover of front-line personnel, organisational restructuring, lack of resources and organisational culture. ${ }^{41} 42$

Process evaluation is valuable to gain insight into why an intervention fails or works, and how it can be optimised. ${ }^{43}$ Qualitative data and follow-up on the implementation process of improvement measures within the intervention wards in the hospital and nursing homes will be a particular focus between the post-test survey measurements (t2 and t3). We will also conduct meetings with key personnel and ward leaders in the control group following the intervention. This is important, as there are continuous events (eg, the patient safety campaign 'In Safe Hands' ${ }^{20}$ ) taking place simultaneously with the intervention programme in an organisational setting. ${ }^{44}$ All such naturally occurring events may add alternative explanations to any differences found between the intervention and the control groups.

Despite the potential limitations of the design, the main contribution of the study will be to contribute to the knowledge of influential components in a cross-level educational programme for healthcare professionals addressing quality and safety in the transitional care of 
the elderly. We will also assess the effects of an educational intervention on reports of patient safety culture, which is yet to be extensively explored in the literature. We will use qualitative and quantitative data collected as part of the intervention and follow-up process to address the feasibility of the intervention strategies. This can form the basis for replicating the intervention within other contexts and in a larger study population and sample.

\section{Author affiliations \\ ${ }^{1}$ Department of Health Studies, University of Stavanger, Stavanger, Norway ${ }^{2}$ Department of Health Services Research and Policy, London School of Hygiene and Tropical Medicine, London, UK \\ ${ }^{3}$ Regional Centre for Age-related Medicine, SESAM, Stavanger University Hospital Stavanger, Stavanger, Norway \\ ${ }^{4}$ Department of Intensive Care, Stavanger University Hospital, Stavanger, Norway}

Acknowledgements The authors would like to thank the members of the Expert Advisory Board of the 'Quality and safety in transitional care of the elderly' project for valuable inputs to the design of the intervention study; Eleanor Robertson, University of Oxford, Jane Sandall, Kings College, Inger Margrethe Siemsen, The Capital Region of Denmark, Doris Østergaard, Danish Institute for Medical Simulation, Erik Hollnagel, University of Southern Denmark, Paul Barach, University of Stavanger, Marit Solheim, Health Trust Førde.

Funding The funding of the study was provided by the Norwegian Research Council (under the title 'Quality and Safety in Elderly Health and Care Services -The role of transitions and interactions') under Grant Agreement No. 204637.

Contributors MS developed the study design, the study protocol and the contents of the intervention programme, including the tools for data collection. $O G$ contributed to the study design, and the drafting and revision of the manuscript. IT contributed to the study design and the drafting and revision of the manuscript. DND contributed to the contents of the intervention programme, the tools for data collection and the content of the manuscript. RNH developed the tools for the data collection and analysis, and commented on the manuscript. KA developed the original proposal for grant application, commented on the contents of the intervention programme, including the tools for data collection, and contributed to drafting and revision of the manuscript. All authors read and approved the final manuscript.

Competing interests None.

Ethics approval The study has been granted ethical approval by the Regional Committees for Medical and Health Research Ethics in Norway, Ref. No. 2011/1978.

Provenance and peer review Not commissioned; peer reviewed for ethical and funding approval prior to submission.

Open Access This is an Open Access article distributed in accordance with the Creative Commons Attribution Non Commercial (CC BY-NC 4.0) license, which permits others to distribute, remix, adapt, build upon this work noncommercially, and license their derivative works on different terms, provided the original work is properly cited and the use is non-commercial. See: http:// creativecommons.org/licenses/by-nc/4.0/

\section{REFERENCES}

1. WHO. Communication During Patient Hand-Overs. Patient Safety Solutions 2007; volum 1; solution 3; May 2007. 2007. http://www. who.int/patientsafety/solutions/patientsafety/PS-Solution3.pdf (accessed 11 Jun 2014).

2. Coleman EA, Boult C. Improving the quality of transitional care for persons with complex care needs. J Am Geriatr Soc 2003;51:556-7.
3. Laugaland KA, Aase $K$, Barach $P$. Adressing risk factors for transitional care of the elderly-literature review. In: Albolino, Bagnara, Bellandi, Llaneza, Rosal, Tartaglia, eds. Health care systems ergonomics and patient safety. London: Taylor \& Francis Group, 2011:183-91.

4. Jeffcott SA, Evans SM, Cameron PA, et al. Improving measurement in clinical handover. Qual Saf Health Care 2009;18:272-7.

5. Nardi R, Scanelli G, Corrao S, et al. Co-morbidity does not reflect complexity in internal medicine patients. Eur J Inter Med 2007; 18:359-68.

6. Storm M, Siemsen IM, Laugaland KA, et al. Quality in transitional care of the elderly: key challenges and relevant improvement measures. Int $J$ Integr Care 2014;14:1-15.

7. Jeffs L, Lyons RF, Merkley J, et al. Clinicians' views on improving interorganizational care transitions. BMC Health Serv Res 2013;13:1-8.

8. Payne S, Kerr C, Hawker S, et al. The communication of information about older people between health and social care practitioners. Age Ageing 2002;31:107-17.

9. Glouberman S, Mintzberg H. Managing the care of health and the cure of disease-part I: differentiation. Health Care Manage Rev 2001;26:56-69.

10. Glouberman S, Mintzberg $\mathrm{H}$. Managing the care of health and the cure of disease-part II: integration. Health Care Manage Rev 2001;26:70-84.

11. Stoyanov S, Boshuizen $\mathrm{H}$, Groene $\mathrm{O}$, et al. Mapping and assessing clinical handover training interventions. BMJ Qual Saf 2012;21:i50-7.

12. Laugaland $K A$, Aase $K$, Barach $P$. Interventions to improve patient safety in transitional care-a review of the evidence. Work 2012;4:2915-24.

13. Dyrstad DN, Testad I, Aase $\mathrm{K}$, et al. A systematic review of the literature on patient participation in transitions of the elderly. Accepted for publication in Special issue of Cognition, Technology and Work 2014.

14. Gordon M, Findley R. Educational interventions to improve handover in health care: a systematic review. Med Educ 2011;(45):1081-9.

15. Philibert I, Barach P. The European HANDOVER Project: a multi-nation program to improve transitions at the primary careinpatient interface. BMJ Qual Saf 2012;21:11-6.

16. Kirsebom M, Wadesten B, Hedstöm M. Communication and coordination during transition of older persons between nursing homes and hospital still in need of improvement. $J$ Adv Nurs 2012;69:884-95.

17. Cooper JB, Singer SJ, Hayes J, et al. Design and evaluation of simulation scenarios for a program introducing patient safety, teamwork, safety leadership, and simulation to healthcare leaders and managers. Simul Healthc 2011;6:231-8.

18. Aase K, Laugaland KA, Dyrstad DN, et al. Quality and safety in transitional care of the elderly: the study protocol of a case study research design (phase 1). BMJ Open 2013;3:e003506.

19. Norwegian Ministry of of Health and Care Services. Samhandlingsreformen: Rett behandling—på rett sted—-til rett tid. St. meld. nr. 47 (2008-2009). [Coordination reform Proper treatment-at the right place and right time. Report no. 47 to the Storting]. Oslo, 2009.

20. Norwegian Ministry of Health and Care Services. I trygge hender Nasjonalt pasientsikkerhetsprogram [The Norwegian Patient Safety Programme: In Safe Hands]. 2011. http://www.pasientsikkerhets programmet.no/no/l+trygge+hender/In+English/The+Norwegian +Patient+Safety+Programme\%3A+In+Safe+Hands.451.cms (accessed 11 Jun 2014).

21. Sexton J, Helmreich R, Neilands T, et al. The safety attitudes questionnaire: psychometric properties, benchmarking data, and emerging research. BMC Health Serv Res 2006;6:44

22. Deilkas E, Hofoss D. Psychometric properties of the Norwegian version of the Safety Attitudes Questionnaire (SAQ), Generic version (Short Form 2006). BMC Health Serv Res 2008:8:191.

23. Clark PG. Examining the interface between interprofessional practice and education: lessons learned from Norway for promoting teamwork. J Interprof Care 2011;25:26-32.

24. Bjørke G, Haavie NE. Crossing boundaries: implementing an interprofessional module into uniprofessional Bachelor programmes. $J$ Interprof Care 2006;20:641-53.

25. Skjørshammer M. Co-operation and conflict in a hospital: interprofessional differences in perception and management of conflicts. J Interprof Care 2001:15:7-18.

26. Castle NG, Wagner LM, Sonon K, et al. Measuring administrators' and direct care workers' perceptions of the safety culture in assisted living facilities. Jt Comm J Qual Patient Saf 2012;38:375-82.

27. Haugen AS, Søfteland E, Eide GS, et al. Impact of the World Health Organization's Surgical Safety Checklist on safety culture in the operating theatre: a controlled intervention study. $\mathrm{Br} J$ Anaesth 2013;110:807-15. 
28. Morello RT, Lowthian JA, Barker AL, et al. Strategies for improving patient safety culture in hospitals: a systematic review. BMJ Qual Saf 2013;22:11-18.

29. Sorra J, Nieva V. Hospital Survey on Patient Safety Culture. Prepared for: Agency for Healthcare Research and Quality (AHRQ), Rockville, MD, 2004

30. Olsen $\mathrm{E}$, Aase K. The challenge of improving safety culture in hospitals: a longitudinal study using hospital survey on patient safety culture. 11th International Probabilistic Safety Assessment and Management Conference and the Annual European Safety and Reliability Conference; 25-29 June 2012. Helsinki, Finland: Curran Associates, Inc.

31. Westat. Nursing home survey on patient safety culture background and information for translators. Prepared for: Agency for Healthcare Research and Quality (AHRQ). Rockville, MD, 2010. http://www. ahrq.gov/professionals/quality-patient-safety/patientsafetyculture/ nursing-home/resources/infotransnhsops.pdf (accessed 25 July 2014).

32. Castle NG, Wagner LM, Perera S, et al. Comparing the safety culture of nursing homes and hospitals. J Appl Gerontol 2011;30:22-43.

33. Nonaka I, Takeuchi $\mathrm{H}$. The knowledge-creating company: how Japanese companies create the dynamics of innovation. New York: Oxford University Press, 1995.

34. Easterby-Smith M, Lyles MA, Tsang EWK. Inter-organizational knowledge transfer: current themes and future prospects. J Manage Stud 2008;45:677-90.

35. West BT, Welch KB, Galecki AT, et al. Linear mixed models: a practical guide using statistical software. Boca Raton, Fla: Chapman \& Hall/CRC, 2007.

36. Lilford RJ, Chilton PJ, Hemming K, et al. Evaluating policy and service interventions: framework to guide selection and interpretation of study end points. BMJ (Clin Res Ed) 2010;341:c4413.
37. Yao GL, Novielli N, Manaseki-Holland S, et al. Evaluation of a predevelopment service delivery intervention: an application to improve clinical handovers. BMJ Qual Saf 2012;21:i29-38.

38. Norwegian Ministry of Health and Care Services. Lov om kommunale helse- og omsorgstjenester [Norwegian Act on municipality health- and care services]. Oslo: Norwegian Ministry of Health and Care Services, 2011. http://lovdata.no/dokument/NL/lov/ 2011-06-24-30?q=lov+om+kommunale+helse+og (accessed $25 \mathrm{Jul}$ 2014).

39. Norwegian Ministry of Health and Care Services. Lov om spesialisthelsetjenesten [Norwegian Act on Specialist Healthcare Services]. Oslo: Norwegian Ministry of Health and Care Services, 1999. http://lovdata.no/dokument/NL/lov/1999-07-02-61?q=lov+om +spesialisthelsetjenester (accessed Jul 25 2014).

40. Cook TD, Campbell DT, Fankhauser G, et al. Quasi-experimentation: design \& analysis issues for field settings. Boston: Houghton Mifflin Co., 1979.

41. Kaplan HC, Brady PW, Dritz MC, et al. The influence of context on quality improvement success in health care: a systematic review of the literature. Milbank Q 2010;88:500-9.

42. Kaplan HC, Provost LP, Froehle CM, et al. The Model for Understanding Success in Quality (MUSIQ): building a theory of context in healthcare quality improvement. BMJ Qual Saf 2012;21:13-20.

43. Medical Research Council. Developing and evaluating complex interventions: new guidance. http://www.mrc.ac.uk/ complexinterventionsguidance, 2006: 39.

44. Øvretveit J. Evaluating health interventions: an introduction to evaluation of health treatments, services, policies, and organizational interventions. Buckingham, England: Open University Press, 1998. 